\title{
Stabilizing Particles of Manganese-iron Oxide with Additives for Thermochemical Energy Storage
}

\author{
N. C. Preisner, ${ }^{*[a]}$ T. Block,${ }^{[b]}$ M. Linder, ${ }^{[a]}$ and H. Leion ${ }^{[c]}$
}

\begin{abstract}
Manganese-iron oxide particles are a promising candidate for both chemical-looping combustion (CLC) and thermochemical energy storage. In CLC, the ability of metal oxides to oxidize fuels in an oxygen-free atmosphere and re-oxidize in air is addressed. Whereas, reaction enthalpy is the main focus of thermochemical energy storage for, e.g. concentrated solar power or an industrial process that requires high temperature levels. Sufficient mechanical strength of the particles while they endure chemical, thermal, or mechanical stress is a crucial factor for both concepts. Particle stability is investigated here by adding $20 \mathrm{wt} \%$ of $\mathrm{TiO}_{2}, \mathrm{ZrO}_{2}$, or $\mathrm{CeO}_{2}$ as a supportive material to $\left(\mathrm{Mn}_{0.7} \mathrm{Fe}_{0.3}\right)_{2} \mathrm{O}_{3}$. Thermal cyclization and temperature shock tests are conducted in a packed bed
\end{abstract}

reactor to identify chemical stability as well as the effect of chemical and thermal stress. A subsequent particle size distribution analysis is performed to determine the relevant breakage mechanism. Attrition resistance is tested with a customized attrition jet cup to estimate the mechanical strength of particles. It is found that the high tendency of unsupported manganese-iron oxide particles towards agglomeration can be improved with any of the chosen additives. The particles with $\mathrm{CeO}_{2}$, and especially with $\mathrm{ZrO}_{2}$, as an additive indicate an increase in resistance towards attrition. However, adding $\mathrm{TiO}_{2}$ has a severe negative impact on the chemical reactivity of the manganese-iron oxide.

\section{Introduction}

The characteristic redox reaction of metal oxides is applied in several research fields, which are motivated by the necessity to mitigate global warming. Metal oxides are currently investigated for example as thermochemical energy storage material, for solar fuel production, and for chemical looping combustion. All of these applications utilize metal oxides in the form of particles and thus rely on a sufficient stability of the particles. Chemical looping combustion (CLC) is based on the ability of metal oxides (oxygen carriers) to oxidize in a reactor with air and carry oxygen to a fuel reactor, where the metal oxides react with gas-phase combustibles. ${ }^{[1]}$ In chemical looping with oxygen uncoupling (CLOU), the metal oxide releases gaseous oxygen in the fuel reactor, which is needed to oxidize not only the gas phase but also liquid and solid fuels. ${ }^{[2]}$ The exhaust gas of the fuel reactor consists of $\mathrm{CO}_{2}$ and $\mathrm{H}_{2} \mathrm{O}$, which can be easily separated. The only exhaust from the air reactor is depleted air. Usually the concept is implemented in the form of two interconnected fluidized beds to allow a continuous operation with biomass, coal, methane, or any other fuel. Reactor setups are tested that range from lab-scale units, ${ }^{[3,4]}$ a $100 \mathrm{~kW}_{\text {th }}$ unit at Chalmers in Sweden, ${ }^{[5]}$ to a $1 \mathrm{MW}_{\text {th }}$ pilot plant at TU Darmstadt, Germany. ${ }^{[6]}$ Recent promising metal oxide candidates are perovskites ${ }^{[7]}$ and Mncombined oxides, e.g. manganese-iron oxides ${ }^{[8]}$ Natural ores are successfully tested. ${ }^{[9]}$ Another application of metal oxides is the production of solar fuels, namely $\mathrm{H}_{2}$ and $\mathrm{CO}$, by splitting $\mathrm{H}_{2} \mathrm{O}$ and $\mathrm{CO}_{2}$ with metal oxides. ${ }^{[10]}$ The produced syngas can be further processed to denser liquid fuels via the Fischer-Tropsch process. The high temperature needed for reducing metal oxides in air is supplied by renewable sources, e.g. a concentrating solar power plant. Implemented reactor concepts focus on porous structured metal oxides ${ }^{[11]}$ in a rotary kiln, ${ }^{[12]}$ moving particles in a fluidized bed reactor, ${ }^{[13]} \mathrm{a}$ cavity reactor, ${ }^{[14]}$ a moving bed reactor, ${ }^{[15-17]}$ and a packed bed reactor. ${ }^{[18-20]}$

Sustainable fuel conversion is the main objective of chemical looping and solar fuel research. However, the reaction enthalpy of the redox reaction is the main objective of thermochemical energy storage research. Thermochemical storage (TCS) systems are a promising way to increase the flexibility of concentrated solar power plants (CSP) or industrial processes operated at high temperature (700$\left.1000^{\circ} \mathrm{C}\right) .{ }^{[21-26]}$ Especially weather instability and expandable operation time can be addressed with TCS systems to lower the cost of CSP and provide dispatchable power generation. ${ }^{[27]}$ The reaction enthalpy of a chemical reversible gas-solid reaction stores heat in the endothermic reaction path and releases heat in the exothermic path. Solid gas redox reactions of metal oxides in air are suitable candidates for exploiting the accessible high temperatures of CSP. Besides applicable reaction temperature, the metal oxide should feature suffi-

[a] N. C. Preisner, Dr. M. Linder

Thermal Process Technology

$D L R$, Institute of Engineering Thermodynamics

Linder Höhe, 51147 Köln, Germany

E-mail: Nicole.Preisner@dlr.de

[b] Dr. T. Block

Structural and Functional Ceramics

$D L R$, Institute of Material Research

Linder Höhe, 51147 Köln, Germany

[c] Dr. H. Leion

Chemistry and Chemical Engineering

Chalmers University of Technology

Kemigården 4, Göteborg, Sweden

Supporting information for this article is available on the WWW under https://doi.org/10.1002/ente.201800211 
cient mechanical strength, fast kinetics, high reaction enthalpy, and cycle stability.

Since oxygen from ambient air can be used as the reaction gas for a thermochemical reaction, no separate gaseous storage is necessary. The concept of two interconnected reactors for continuous charging and discharging is presented by Schrader et al. ${ }^{[2]}$ with $\mathrm{CoO}$ as thermochemical storage material and heat transfer medium. A solar reactor for reduction and an oxidation reactor are combined with cold and hot storage tanks to feed an air Brayton cycle. For this reason, the storage capacity and power are decoupled, allowing the separate adjustment of both power and capacity. In these continuous reactors, it is possible to extract thermochemical and sensible thermal energy and, thus, increase the energy density of metal oxide particles. So far, solar receivers for the reduction of metal oxide particles by direct solar radiation apply rotary kiln, ${ }^{[29,30]}$ gravity-driven particle receivers ${ }^{[31,32]}$ or packed bed reactors. ${ }^{[33]}$ A fluidized bed reactor ${ }^{[35]}$ and packed bed reactors ${ }^{[25,34]}$ were investigated for reactors that are able to oxidize metal oxide particles and extract heat to a working fluid. A further development of the packed bed to a moving bed as a reactor concept for continuous heat extraction combines two main advantages. First, thermochemical as well as sensible heat can be extracted from the metal oxide particles to improve overall efficiency, while a stable temperature of a working fluid is allowed. Second, no moving reactor components at high temperatures need to be handled since particles are transported by gravity in contrast to continuous reactors like rotary kiln or sintering bands.

Manganese-iron oxides have an equilibrium temperature in air atmosphere between $900^{\circ} \mathrm{C}$ and $1400^{\circ} \mathrm{C}$, depending on the manganese-to-iron ratio. Thermodynamic investigations of the manganese-iron-oxygen system in air identify the cubic bixbyite phase $\left[\left(\mathrm{Fe}^{3+}, \mathrm{Mn}^{3+}\right)_{2} \mathrm{O}_{3}\right]$, and the trigonal hematite phase $\left(\mathrm{Fe}_{2} \mathrm{O}_{3}\right)$ at low temperatures and the cubic spinel phase $\left[\left(\mathrm{Fe}^{2+}, \mathrm{Mn}^{2+}\right)\left(\mathrm{Fe}^{3+}, \mathrm{Mn}^{3+}\right)_{2} \mathrm{O}_{4}\right]$, and tetragonal hausmannite phase $\left[\left(\mathrm{Mn}^{2+}\right)\left(\mathrm{Mn}^{3+}\right)_{2} \mathrm{O}_{4}\right]$ at high temperatures as thermodynamically stable phases. ${ }^{[36-39]}$ The oxides are non-toxic and show acceptable reaction time for oxidation and reduction as well as cycle stability. Several studies have investigated the redox behavior of manganese-iron-oxide systems with different manganese-iron ratios for thermochemical applications. ${ }^{[22,40-42]}$ Equation (1) presents the global reaction of manganese-iron oxides between bixbyite and spinel, which can be initiated by changing oxygen partial pressure or/and temperature.

$6\left(\mathrm{Mn}_{\mathrm{x}} \mathrm{Fe}_{1-\mathrm{x}}\right)_{2} \mathrm{O}_{3} \rightleftharpoons 4\left(\mathrm{Mn}_{\mathrm{x}} \mathrm{Fe}_{1-\mathrm{x}}\right)_{3} \mathrm{O}_{4}+\mathrm{O}_{2}(\mathrm{~g})$

A stoichiometric weight change caused by the redox reaction of 3.340 to $3.378 \%$ with the $\mathrm{Mn}$-cation content $(\mathrm{Mn} /$ $\mathrm{Mn}+\mathrm{Fe}) \mathrm{x}$ between 0 and 1 can theoretically be achieved. However, agglomeration and particle stability problems occur after a number of redox reactions of $\left(\mathrm{Mn}_{0.75} \mathrm{Fe}_{0.25}\right)_{2} \mathrm{O}_{3}$ granules in a packed bed reactor. ${ }^{[34]}$ Under chemical looping conditions, similar problems with manganese-iron-oxide particles in a fluidized bed reactor have been reported. ${ }^{[43]} \mathrm{A}$ reactor concept with moving particles, such as a reactor with a moving bed or a fluidized bed, induces even greater stress on the particles than a packed bed. The attrition of particles results in the loss of material when small particles must be removed and a recycling or filtration system becomes necessary. Moreover, decreasing particle size causes higher pressure losses and, thus, lowers the performance of a reactor setup.

Particles undergo several kinds of stress in a reactor, such as chemical, mechanical, and thermal stress. As a consequence, particles may split, become fatigued, fractures may spall, or the surface may be smoothed due to attrition or abrasion, leading to a shift in particle size distribution. Mechanical stress includes particle-wall or particle-particle collision. When the kinetic energy of a collision at high velocity is absorbed, particles may fracture or be abraded. A low velocity collision causes surface abrasion resulting in very fine particles by smoothing the small edges on the particle. Particles endure thermal stress in the form of high heating or cooling rates, temperature gradients inside the particle, or different thermal expansion coefficients of multiphase particles. ${ }^{[44]}$ Chemical reactions can cause stress when phases with different densities or molar volumes are formed, resulting in intraparticle stresses, e.g. the reduction of $\mathrm{Fe}_{2} \mathrm{O}_{3}$ caused by the expansion of ferrite oxide crystals. ${ }^{[45]} \mathrm{A}$ change in pore structure may weaken the overall particle,${ }^{[46]}$ and the release of gas during a reaction can cause an internal pressure gradient in gas-solid reactions.

The agglomeration tendency of particles is an important criterion for the expected useful lifetime of any thermochemical storage material. Agglomeration can be caused by a temperature exceeding the onset sinter temperature, chemical reactions, or particle-collision-induced melting. ${ }^{[45,47,48]}$ Since any change in particle size distribution may have a tremendous impact on reactor performance, possibilities to improve the particle stability of chemically reacting Manganese-iron oxides are addressed in this paper.

Particle strength can be improved by adjustments made in the particle preparation, for instance, by choosing sol-gel granulation, spray drying, using precipitation methods, or by adding binders. Coating with a strong porous material can also strengthen particles as well as introducing compressive stresses by rapid heating and cooling of particles to harden the particle surface without sintering or phase changes. ${ }^{[4]}$

The fluidized bed concept utilized in CLC can cause the severe attrition of oxygen carrier particles. Thus, in the research field of chemical looping, great effort has been put into improving, measuring, and predicting the strength of metal oxide particles and their agglomeration tendency. ${ }^{[50]}$ Adding supportive inert material, optimizing the calcination temperature, or choosing an adapted preparation method have shown promising results. Azimi et al. ${ }^{[1]}$ have investigated the effect of different additives (40 wt.\%) to spraydried $\left(\mathrm{Mn}_{0.75} \mathrm{Fe}_{0.25}\right)_{2} \mathrm{O}_{3}$ particles on mechanical strength and reactivity under chemical-looping conditions. Attrition resistance was found to be substantially improved with the addition of $\mathrm{ZrO}_{2}$ (monoclinic), depending on the calcination temper- 
ature of the particles. For this reason, the use of a rather low calcination temperature is recommended. ${ }^{[51]}$ A fixed amount of 7 wt. $\% \mathrm{TiO}_{2}$ was added by the authors of ${ }^{[52]}$ for its reactivity and magnetic properties to manganese-iron oxides with a $\mathrm{Mn}: \mathrm{Fe}$ ratio between 0 and 1 and under chemical looping conditions. An increase in crushing strength was found compared to particles without the addition of Ti.

Particle stability and the modification of metal oxides have been comprehensively investigated by the chemicallooping research community. ${ }^{[46,53-55]}$ However, operation conditions and applied reactor concepts differ between chemicallooping and thermochemical storage applications. In CLC, isothermal reaction conditions are mainly applied in $\mathrm{O}_{2}$ depleted air for the oxidation of metal oxides, and a fuel atmosphere for the reduction of metal oxides. ${ }^{[2]}$ In contrast, in the thermochemical storage concept, the reduction in $\mathrm{O}_{2}$ depleted air and oxidation in air are initiated thermally by exceeding the equilibrium temperature or by changing the partial pressure of $\mathrm{O}_{2}$ under isothermal conditions. ${ }^{[34]}$ Particle size may vary depending on the applied reactor concept. For these reasons, it remains uncertain if the findings from particle stability investigations under chemical-looping conditions can be applied to thermochemical storage applications. This paper presents an investigation of the effect of the addition of $\mathrm{ZrO}_{2}, \mathrm{CeO}_{2}$, or $\mathrm{TiO}_{2}$ to manganese-iron oxide on reactivity, agglomeration, and attrition behavior under the specific conditions relevant for thermochemical storage using a moving bed reactor.

\section{Results and Discussion}

\section{Characterisation of the Material}

A manganese-iron oxide with a $\mathrm{Mn} / \mathrm{Mn}+\mathrm{Fe}$ ratio of 0.7 was chosen as a promising thermochemical storage material due to its suitable redox reaction time and temperature, cycle stability and reaction enthalpy. ${ }^{[22,41,42]}$ To further improve the mechanical strength of the material, $\mathrm{ZrO}_{2}, \mathrm{CeO}_{2}$, or $\mathrm{TiO}_{2}$ was added as a support, each equaling $20 \mathrm{wt} \%$ of the particle composition. Detailed composition and material properties are given in Table 1. The composition specifies the weight fraction of raw materials used for producing the particles.

Scanning electron microscopy was used to characterize the microstructures of all untreated samples (Figure 1). Internal imperfections are visible in the polished microsections in the figure. Further investigation with EDX indicated iron-rich, manganese-rich, and additive-rich regions. A bimodal grain distribution with larger Fe-rich regions and smaller Mn-rich regions was identified in the $\left(\mathrm{Mn}_{0.7} \mathrm{Fe}_{0.3}\right)_{2} \mathrm{O}_{3}$ particles. The internal distribution of the additive material seemed to increase in heterogeneity from Zr-cation, Ti-cation, to Cecation. Detailed data can be found as supporting information.

\begin{tabular}{|llll|}
\hline \multicolumn{3}{|l|}{ Table 1. Composition and bulk density of manganese-iron-oxide materials. } \\
Acronym ${ }^{[a]}$ & $\begin{array}{l}\text { Molar } \\
\text { Composition }\end{array}$ & $\begin{array}{l}\text { Composition of } \\
\text { raw materials } \\
\text { (wt.\%) }\end{array}$ & $\begin{array}{l}\text { Bulk } \\
\text { density } \\
\left(\mathrm{kg} \mathrm{m}^{-3}\right)\end{array}$ \\
\hline Mn70Fe30 & $\left(\mathrm{Mn}_{0.7} \mathrm{Fe}_{0.3}\right)_{2} \mathrm{O}_{3}$ & $\begin{array}{l}69 \% \mathrm{Mn}_{3} \mathrm{O}_{4} \\
\text { Mn70Fe30_Zr20 }\end{array}$ & 1330 \\
& $\left(\mathrm{Mn}_{0.7} \mathrm{Fe}_{0.3}\right)_{2} \mathrm{O}_{3} / \mathrm{ZrO}_{2}$ & $\begin{array}{l}31 \% \mathrm{Fe}_{2} \mathrm{O}_{3} \\
55.2 \% \mathrm{Mn}_{3} \mathrm{O}_{4}\end{array}$ & 1539 \\
& & $24.8 \% \mathrm{Fe}_{2} \mathrm{O}_{3}$ & \\
& & $20 \% \mathrm{ZrO}_{2}$ \\
Mn70Fe30_Ce20 & $\left(\mathrm{Mn}_{0.7} \mathrm{Fe}_{0.3}\right)_{2} \mathrm{O}_{3} / \mathrm{CeO}_{2}$ & $\begin{array}{l}55.2 \% \mathrm{Mnn}_{3} \mathrm{O}_{4} \\
24.8 \% \mathrm{Fe}_{2} \mathrm{O}_{3}\end{array}$ & 1366 \\
& & $20 \% \mathrm{CeO}_{2}$ \\
Mn70Fe30_Ti20 & $\left(\mathrm{Mn}_{0.7} \mathrm{Fe}_{0.3}\right)_{2} \mathrm{O}_{3} / \mathrm{TiO}_{2}$ & $55.2 \% \mathrm{Mnn}_{3} \mathrm{O}_{4}$ & 1193 \\
& & $24.8 \% \mathrm{Fe}_{2} \mathrm{O}_{3}$ & \\
& & $20 \% \mathrm{TiO}_{2}$ \\
\hline
\end{tabular}

[a] The acronym describes the molar ratio of $\mathrm{Mn}$ and $\mathrm{Fe}$ cations and the weight fraction of added $\mathrm{ZrO}_{2}, \mathrm{TiO}_{2}$, or $\mathrm{CeO}_{2}$.

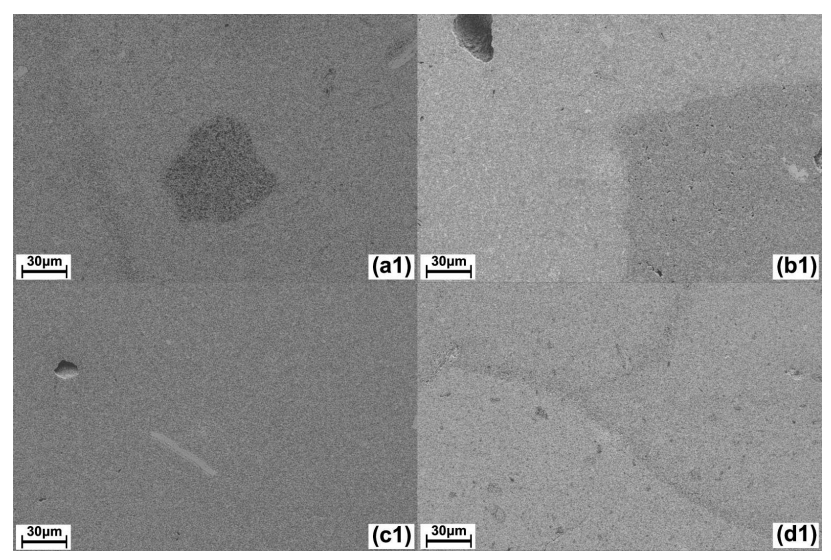

Figure 1. SEM profile image with $5.0 \mathrm{kV}$ acceleration voltage and working distances of $8.0 \mathrm{~mm} \mathrm{(a,c,d)} \mathrm{and} 7.9 \mathrm{~mm}(\mathrm{~b})$ of untreated Mn70Fe30 (a1), Mn70Fe30_Ce20 (b1), Mn70Fe30_Ti20 (c1), and Mn70Fe30_Zr20 (d1).

\section{Effect of Additives on Energy Storage Density}

A modification with inert additives potentially lowers the total energy density, since inert additives do not contribute to the thermochemical share in energy density. Regarding the sensible thermal energy stored in the particles, a supportive material with high heat capacity should be favored in case of thermochemical energy storage application, whereas a lower heat capacity is beneficial in case of CLC application. Rutile $\left(\mathrm{TiO}_{2}\right)$ offers the highest mean heat capacity of $934.04 \mathrm{~J} \mathrm{~kg}^{-1} \mathrm{~K}^{-1}$ for temperatures between $600 \mathrm{~K}$ and $1300 \mathrm{~K}$, followed by ceria $\left(\mathrm{CeO}_{2}\right)$ with $603.56 \mathrm{~J} \mathrm{~kg}^{-1} \mathrm{~K}^{-1}$ and zirconia $\left(\mathrm{ZrO}_{2}\right)$ featuring $450.24 \mathrm{~J} \mathrm{~kg}^{-1} \mathrm{~K}^{-1} \cdot{ }^{[56]}$ However, the bulk density of manganese-iron oxides with the addition of $\mathrm{ZrO}_{2}$ is slightly higher than with the addition of $\mathrm{TiO}_{2}$, which affects the volumetric energy density of the storage material. When inert, the support material does not contribute to the thermochemical share of energy density.

According to reaction equation (1), a stoichiometric mass loss of $3.366 \%$ can be calculated for pure $\left(\mathrm{Mn}_{0.7} \mathrm{Fe}_{0.3}\right)_{2} \mathrm{O}_{3}$. The additive, when behaving inert, reduces the stoichiometric mass loss to $2.693 \%$ for $\left(\mathrm{Mn}_{0.7} \mathrm{Fe}_{0.3}\right)_{2} \mathrm{O}_{3}$ with $20 \mathrm{wt}$ \% of $\mathrm{ZrO}_{2}$, 


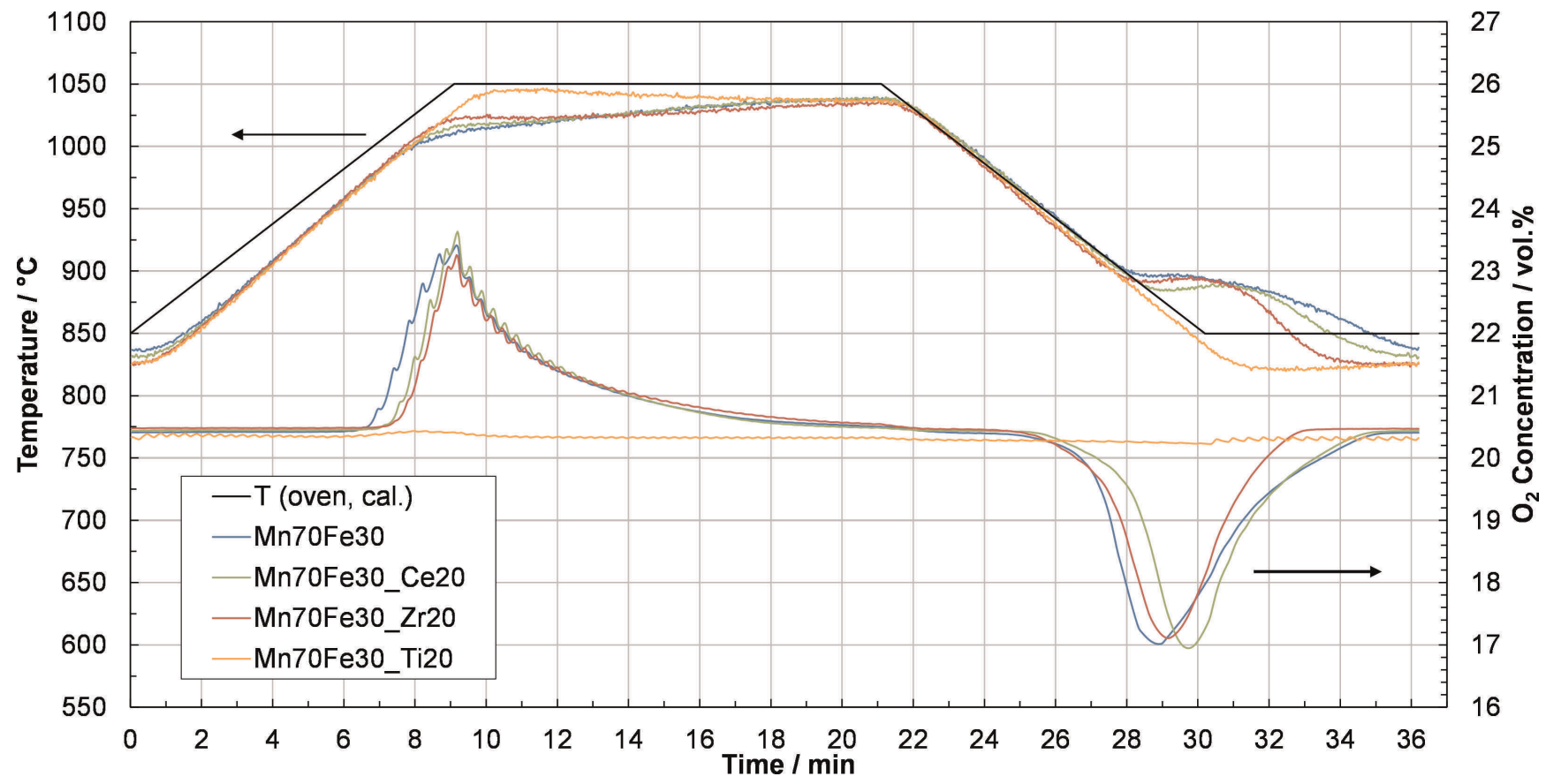

Figure 2. Measured bed temperature and set point temperature of the $25^{\text {th }}$ cycle (upper curves) and $\mathrm{O}_{2}$ concentration (lower curves) of $25^{\text {th }}$ cycle of thermal cyclization in lab-scale packed bed reactor with pure $\left(\mathrm{Mn}_{0.7} \mathrm{Fe}_{0.3}\right)_{2} \mathrm{O}_{3}$ or supported with $\mathrm{TiO}_{2}, \mathrm{ZrO}_{2}$, or $\mathrm{CeO}_{2}$.

$\mathrm{TiO}_{2}$, or $\mathrm{CeO}_{2}$. Thermogravimetric measurements with Mn70Fe30, Mn70Fe30_Zr20, or Mn70Fe30_Ce20 confirmed the stoichiometric mass loss of equation (1) with a deviation of 0.04-0.06 wt.\%. Whereas Mn70Fe30_Ti20 showed a higher mass loss during reduction than pure Mn70Fe30, indicating that equation (1) is not the predominant reduction reaction under the given conditions.

\section{Effect of Thermal Cyclization}

The effects of chemical and thermal stress on supported manganese-iron oxide particles were investigated and quantified in the study. The experiments were conducted in a packed bed reactor to inhibit any friction of the material.

The effect of chemical stress on the particle stability and the reactivity of pure manganese-iron oxide and manganeseiron oxide with the addition of $\mathrm{CeO}_{2}, \mathrm{ZrO}_{2}$, or $\mathrm{TiO}_{2}$ were investigated with thermal cyclization tests. The reduction and oxidation was initiated by changing the set point temperature of the oven between $850^{\circ} \mathrm{C}$ and $1050^{\circ} \mathrm{C}$ for 30 cycles.

The ability of manganese-iron oxides with different supporting additives to perform reversible redox reactions in air is illustrated in Figure 2 with the exemplary $25^{\text {th }}$ cycle. An increase in $\mathrm{O}_{2}$ concentration denotes the reduction to $\left(\mathrm{Mn}_{0.7} \mathrm{Fe}_{0.3}\right)_{3} \mathrm{O}_{4}$, and a decrease in $\mathrm{O}_{2}$ concentration denotes the oxidation to $\left(\mathrm{Mn}_{0.7} \mathrm{Fe}_{0.3}\right)_{2} \mathrm{O}_{3}$ for $\mathrm{Mn} 70 \mathrm{Fe} 30$ according to equation (1). The $\mathrm{O}_{2}$ concentration in the exhaust gas of Mn70Fe30_Ti20 during thermal cyclization indicated no relevant reduction or oxidation of the material, whereas pure $\left(\mathrm{Mn}_{0.7} \mathrm{Fe}_{0.3}\right)_{2} \mathrm{O}_{3}$ and the samples supported with $\mathrm{CeO}_{2}$ and
$\mathrm{ZrO}_{2}$ were reduced and oxidized in air atmosphere. The increase in $\mathrm{O}_{2}$ concentration up to a peak of around $23.5 \%$ or reduction down to around $17 \%$ was similar for the three remaining compositions, but varied in time and in temperature. The area under the $\mathrm{O}_{2}$ line correlates to the extent of conversion. During the reduction of the 25th cycle, Mn70Fe30 reached the highest reduction conversion, even though the reactive mass was identical for the three samples. A detailed analysis of the oxidation conversion is given in Figure 3. The endothermic reduction started at around $971^{\circ} \mathrm{C}$, which limited the bed temperature during heating and the subsequent isothermal phase. The initiation temperature of reduction, however, seemed to decrease between Mn70Fe30_Zr20, Mn70Fe30_Ce20 to Mn70Fe30. The exothermic oxidation began slowly at around $966^{\circ} \mathrm{C}$ and led to a temperature plateau in the range of $895^{\circ} \mathrm{C}$ for $\mathrm{Mn} 70 \mathrm{Fe} 30$ and $\mathrm{Mn} 70 \mathrm{Fe} 30$ $\mathrm{Zr} 20$ and around $889^{\circ} \mathrm{C}$ for $\mathrm{Mn} 70 \mathrm{Fe} 30 \_\mathrm{Ce} 20$ during the cooling phase. The initiation temperatures of reduction and oxidation of $\mathrm{Mn70Fe30}$ and $\mathrm{Mn70Fe30 \_ Ce20} \mathrm{were} \mathrm{stable}$ during 30 temperature cycles and were in agreement with reported equilibrium temperatures in phase diagrams. ${ }^{[36,37,39]}$ The initiation temperature of reduction and oxidation of Mn70Fe30_Zr20 showed a slight increase during cyclization from $975^{\circ} \mathrm{C}$ to $983^{\circ} \mathrm{C}$ in case of reduction and from $960^{\circ} \mathrm{C}$ to $972^{\circ} \mathrm{C}$ in case of oxidation. The conversion presented in Figure 3 was calculated as oxygen loss in the gas stream due to the oxidation of the particles relative to the stoichiometric oxygen uptake of the active manganese-iron oxide content, for the $2^{\text {nd }}$ and last performed oxidations.

Only 28 cycles could be performed for Mn70Fe30_Zr20 due to practical reasons, while 30 cycles were conducted with 


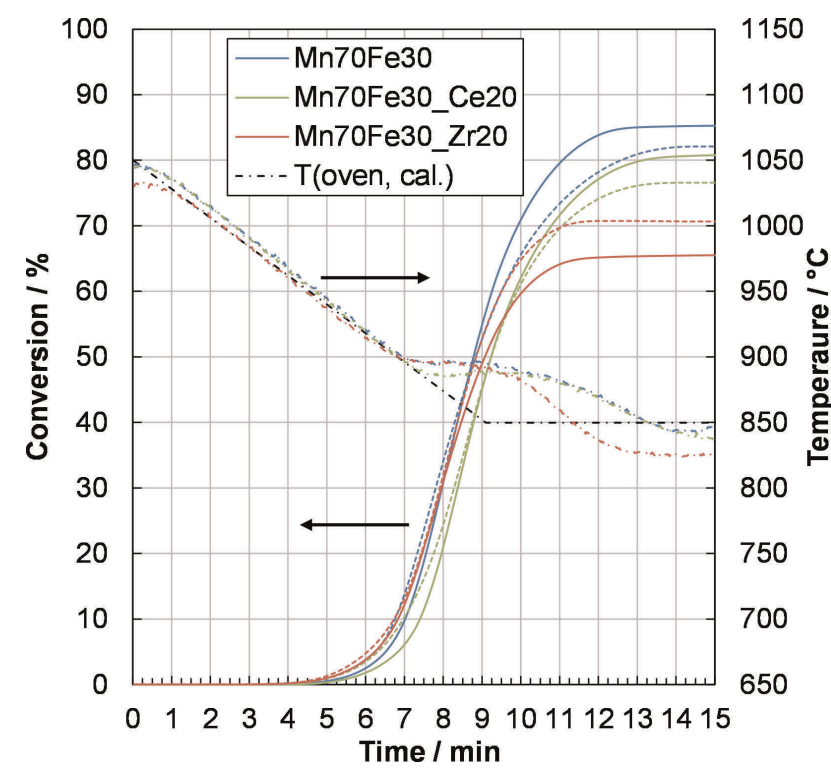

Figure 3. Oxidation conversion of Mn70Fe30 (blue), Mn70Fe30_Ce20 (green), and Mn70Fe30_Zr20 (red), relative to the stoichiometric oxygen uptake of the active manganese-iron oxide content in the sample, during the 2 nd $(-)$ and 28th (Mn70Fe30_Zr20) or 30th (--) cycle of thermal cyclization in a packed bed reactor. The bed temperature (-•-) is displayed for the 2 nd cycle of each composition as well as the set point temperature of the kiln.

the other displayed compositions. Each sample has been cooled to ambient temperature in air between the two displayed cycles, because the cyclization was performed on two consecutive days. The given time started at the end of the isothermal step at $1050{ }^{\circ} \mathrm{C}$. No conversion calculations were performed for Mn70Fe30_Ti20 since the $\mathrm{O}_{2}$ concentration in the exhaust gas indicated only minor reduction and oxidation after one reduction during the first cycle. A detailed depiction of the occurring phases is presented in Figure 8-11. The manganese-iron oxides with the addition of $\mathrm{CeO}_{2}$ and $\mathrm{ZrO}_{2}$ showed a lower conversion than $\mathrm{Mn} 70 \mathrm{Fe} 30$. While $85.2 \%$ of the pure $\mathrm{Mn} 70 \mathrm{Fe} 30$ sample could be oxidized during the $2^{\text {nd }}$ cycle, Mn70Fe30_Ce20 and Mn70Fe30_Zr20 reached a total conversion of $80.8 \%$ and $65.5 \%$, respectively. The length of the temperature plateaus in Figure 3 reflects the discrepancy between achieved conversion values, and the plateau formation is directly related to the highest oxidation rate. The conversion trend of Mn70Fe30 and Mn70Fe30_Ce20 declined with increasing cyclization number and showed no continuous effect of the prolonged oxidizing conditions while the reactor was cooled to ambient temperature after one day of experiments. In contrast, the cooling-down phase of a Mn70Fe30 Zr20 packed bed significantly improved the conversion of the redox reaction, resulting in an increase in conversion for the $28^{\text {th }}$ cycle of $70.75 \%$. Furthermore, the reaction time needed to achieve $0.1 \%$ to $50 \%$ conversion increased for $\mathrm{Mn} 70 \mathrm{Fe} 30$ and Mn70Fe30_Ce20 from the $2^{\text {nd }}$ to the $30^{\text {th }}$ cycle. Up to this point, Mn70Fe30 and Mn70Fe30_Ce20 seemed to be the most promising candidates as energy storage material with respect to oxidation behavior. It should be noted that the oxidation conversion of Mn70Fe30_Zr20 benefited most of the pro- longed oxidation during the cooling of the packed bed between day 1 and 2. For this reason, a longer isothermal step may improve the cycle stability.

To eliminate the influence of the experimental conditions on the conversion results, the mass loss during 30 cycles of each material was measured with a simultaneous thermal analyzer. The temperature profile and the gas atmosphere was adjusted according to thermal cyclization conditions. The conversion of the $2^{\text {nd }}, 15^{\text {th }}$, and $30^{\text {th }}$ cycle was normalized with the stoichiometric mass loss (Table 2). After a mass loss of

\begin{tabular}{|c|c|c|c|c|c|c|}
\hline \multirow[t]{2}{*}{ Material } & \multicolumn{2}{|l|}{ Cycle 2} & \multicolumn{2}{|l|}{ Cycle 15} & \multicolumn{2}{|l|}{ Cycle 30} \\
\hline & Red. & Ox. & Red. & Ox. & Red. & Ox. \\
\hline $\mathrm{Mn} 70 \mathrm{Fe} 30$ & $92.4 \%$ & $91.5 \%$ & $92.1 \%$ & $91.8 \%$ & $92.4 \%$ & $91.2 \%$ \\
\hline Mn70Fe30_Zr20 & $92.8 \%$ & $92.1 \%$ & $91.3 \%$ & $91.7 \%$ & $92.1 \%$ & $91.3 \%$ \\
\hline Mn70Fe30_Ce20 & $92.1 \%$ & $92.1 \%$ & $91.7 \%$ & $91.4 \%$ & $91.4 \%$ & $89.9 \%$ \\
\hline
\end{tabular}

$1.40 \%$ during the first reduction of $\mathrm{Mn} 70 \mathrm{Fe} 30 \_\mathrm{Ti} 20$, only minor mass changes were observed in subsequent cycles. All materials, except Mn70Fe30_Ti20, showed stable conversion rates over 30 cycles with thermal cyclization conditions.

A particle size distribution analysis can reveal the predominant breakage mechanism. Therefore, the distribution before and after a treatment that caused stress to the particles was compared. ${ }^{[58]}$ In the differential particle size distribution plot (Figure 4), positive weight fractions denote an increase in the weight fraction for the given particle size, whereas a negative value corresponds to a decrease in the weight fraction for the given particle size. All samples were treated in a vibrating machine for 10 minutes to separate the different particle sizes according to the mesh sizes of the sieves.

The particle size distribution of untreated Mn70Fe30_ $\mathrm{Ce} 20$ is included to illustrate the original particle size distribution of all the tested materials, which showed a very similar distribution. The Mn70Fe30 sample showed a high tendency towards agglomeration as indicated by particle sizes above the original $2-3 \mathrm{~mm}$. In addition, the disintegration mechanism led to the production of fines for Mn70Fe30 after 30 cycles, which is displayed enlarged in the right corner. An image of a Mn70Fe30 agglomerate and $\mathrm{Mn} 70 \mathrm{Fe} 30$ fines is presented in Figure 5 and Figure 6, respectively. The bed volume of $\mathrm{Mn} 70 \mathrm{Fe} 30$ particles increased by $17 \%$, which could represent a particle "swelling" and result in an increased amount of particles in the diameter range of 3-4 mm. Wokon et al. ${ }^{[42]}$ have reported a similar effect for $\left(\mathrm{Mn}_{0.75} \mathrm{Fe}_{0.25}\right)_{2} \mathrm{O}_{3}$ particles in the size range of $1-3 \mathrm{~mm}$ after 100 redox cycles. In addition, Brown et al. ${ }^{[46]}$ have described an increase in the swelling effect for pure iron oxide particles, when they performed continuing redox reactions between $\mathrm{Fe}_{2} \mathrm{O}_{3}$ and $\mathrm{Fe}_{3} \mathrm{O}_{4}$ phase. The authors identified the formation of a porous instead of a lamella magnetite as the crucial point, and this 


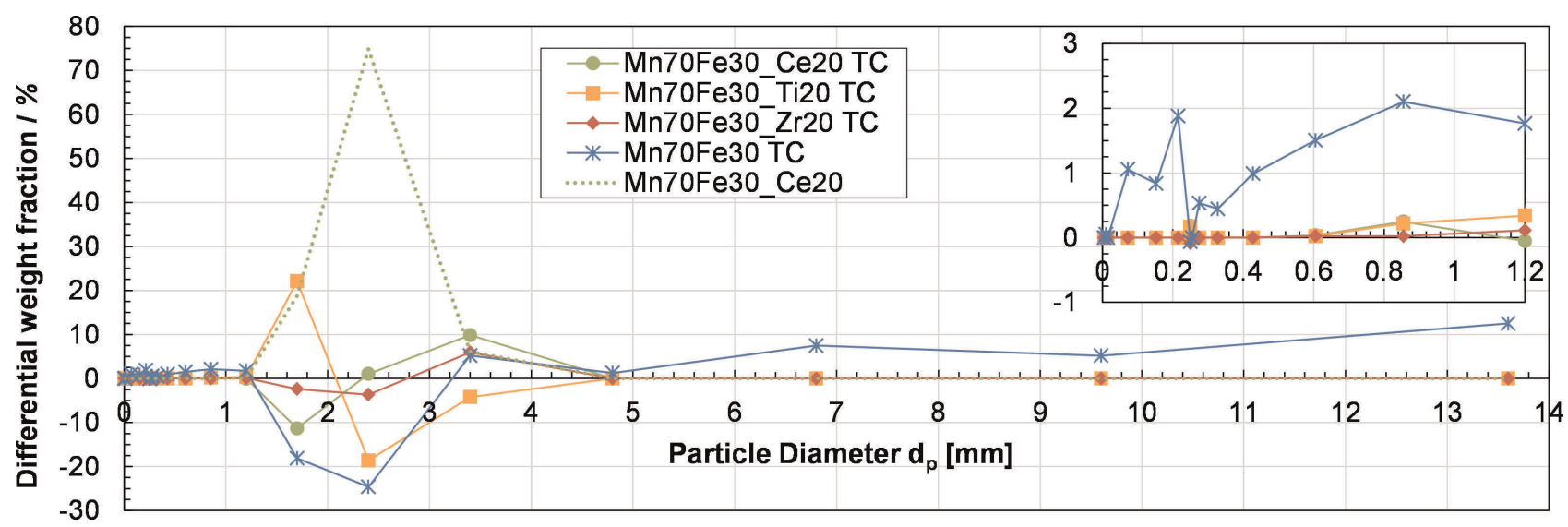

Figure 4. Differential particle size distribution of pure $\left(\mathrm{Mn}_{0.7} \mathrm{Fe}_{0.3}\right)_{2} \mathrm{O}_{3}$ and manganese-iron oxide with supporting additives after 30 cycles of thermal cyclization (TC) in a packed bed reactor compared to untreated particle size distribution with a close up of 0 to $1.2 \mathrm{~mm}$ particle size in the upper right corner. The values display the difference between the weight fraction of each measured particle size range before and after particle treatment in a packed bed reactor. The green dotted line symbolizes original particle size distribution before any treatment. The plotted particle size was calculated as arithmetic mean particle size of the sieve sizes.

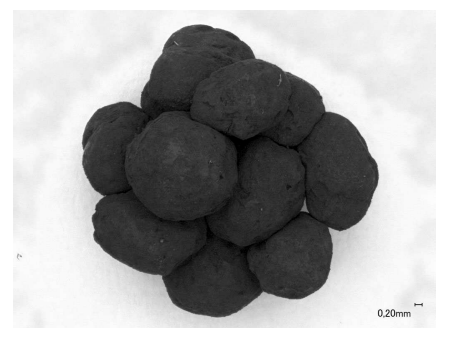

Figure 5. Mn70Fe30 agglomerate after 30 temperature cycles.

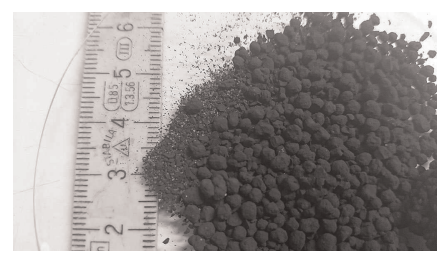

Figure 6. Mn70Fe30 bulk after 30 temperature cycles.

resulted in fragile particles with a tendency towards fragmentation. Carrillo et al. ${ }^{[41]}$ suspect that sintering processes, or more precisely, a complete morphology change caused by high temperature conditions for the reduction and oxidation of $\mathrm{Mn}_{2} \mathrm{O}_{3} / \mathrm{Mn}_{3} \mathrm{O}_{4}$ or $(\mathrm{Mn}, \mathrm{Fe})_{2} \mathrm{O}_{3} /(\mathrm{Mn}, \mathrm{Fe})_{2} \mathrm{O}_{3}$ systems, are responsible for low re-oxidation rates. Those authors present sintering as a combination of densification and coarsening phenomena. They suggest that the sintering process impedes oxygen diffusion through $\mathrm{Mn}_{3} \mathrm{O}_{4}$ layers because of reduced active surface or particle aggregation.

In contrast to $\mathrm{Mn} 70 \mathrm{Fe} 30$, all supported manganese-iron oxides showed no rise in bed volume height after 30 temperature cycles. All the supportive materials obviously impeded the agglomeration phenomenon to a minimum. Mn70Fe30 Ce20 and Mn70Fe30_Zr20 particles showed a redistribution of particle size from the lower end of original particle size to slightly larger particles. Some particles must have agglom- erated, since no "swelling" effect could be observed. In contrast, Mn70Fe30_Ti20 particles tended towards breakage instead of disintegration and showed no agglomeration phenomenon.

In order to better understand and support the above findings, a detailed analysis of the morphology of the samples was performed. SEM images showed enlarged grains with irregular morphology in a comparison of the particle surface after thermal cyclization of Mn70Fe30, Mn70Fe30_Ti20, Mn70Fe30_Ce20, and Mn70Fe30_Zr20 (Figure 7) with untreated material.

The addition of $\mathrm{ZrO}_{2}$ in particular seemed to reduce grain growth on particle surface during thermal cyclization (Figure 7 c1-c2). In a comparison of manganese-iron oxide with the addition of $\mathrm{CeO}_{2}, \mathrm{ZrO}_{2}$, or $\mathrm{TiO}_{2}, \mathrm{Mn} 70 \mathrm{Fe} 30 \_\mathrm{Ce} 20$ developed the largest and most irregular surface grains and the most agglomerates, which is in agreement with the agglomeration tendency after redox reactions in air, indicated by the differential particle size distribution (Figures 4 and 12a).

XRD analyses of samples after thermal cyclization (Figures 8-11) suggested that $\mathrm{ZrO}_{2}$ and $\mathrm{CeO}_{2}$ are mostly inert additives to $\left(\mathrm{Mn}_{0.7} \mathrm{Fe}_{0.3}\right)_{2} \mathrm{O}_{3}$. This is in agreement with Bhavsar et al. ${ }^{[48]}$ However, the $\mathrm{CeO}_{2}$-supported manganese-iron oxide sample was not completely oxidized after thermal cyclization with subsequent cooling to ambient temperature in air. Furthermore, the $\mathrm{TiO}_{2}$-supported manganese-iron oxide sample formed an iron-titanate phase, detected as pseudobrookite $\left(\mathrm{Fe}_{2} \mathrm{TiO}_{5}\right)$ with XRD, which also detected bixbyite $\left(\mathrm{Mn}_{2} \mathrm{O}_{3}\right)$ and hematite $\left(\mathrm{Fe}_{2} \mathrm{O}_{3}\right)$. According to Anovitz et al., ${ }^{[62]}$ pseudobrookite is formed from hematite $\left(\mathrm{Fe}_{2} \mathrm{O}_{3}\right)$ and rutile $\left(\mathrm{TiO}_{2}\right)$ and remains stable above $585^{\circ} \mathrm{C}$, which explains the poor reactivity of this sample (see Figure 2 ). Therefore, pseudobrookite could have been already formed during the preparation process of the Mn70Fe30_Ti20 particles.

Thermal cyclization experiments focused mainly on chemical stress, but it must be noted that by initiating the redox 


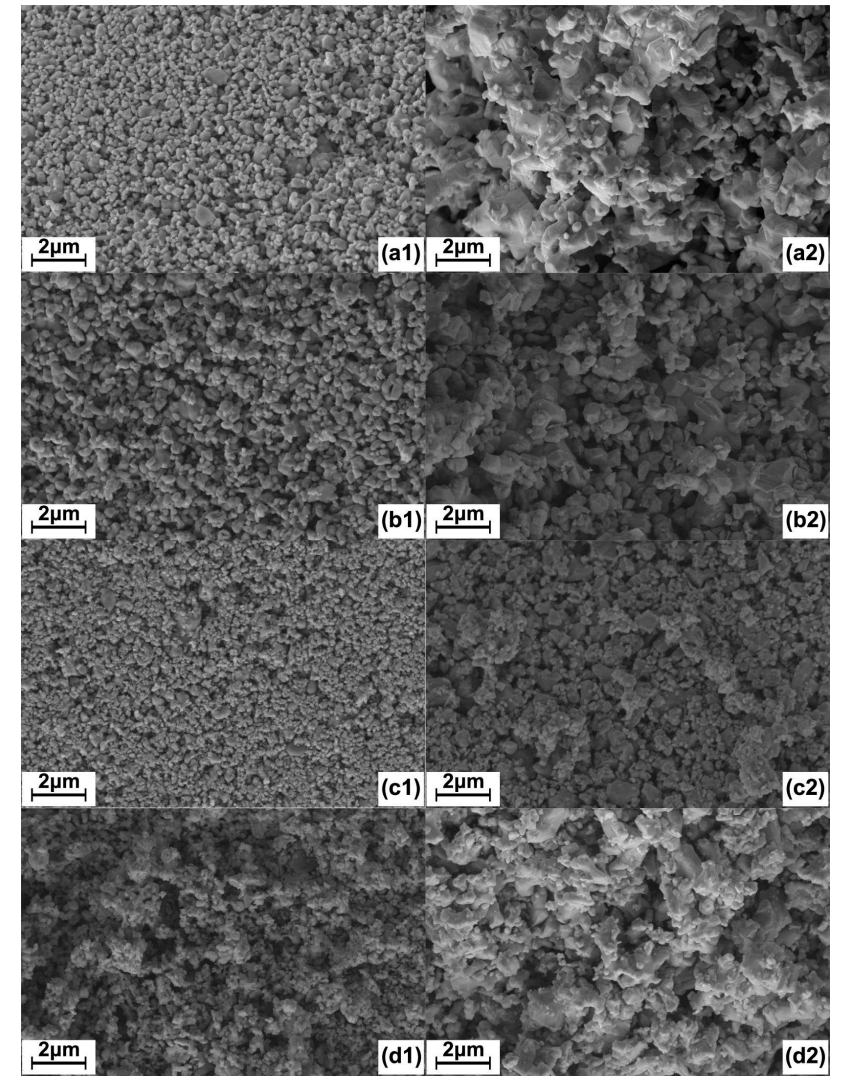

Figure 7. SEM images with $5.0 \mathrm{kV}$ acceleration voltage and working distances $8.0 \mathrm{~mm}(\mathrm{al}, \mathrm{bl}, \mathrm{b} 2, \mathrm{cl}, \mathrm{c} 2$ and d1, d2) and $7.9 \mathrm{~mm}(\mathrm{a} 2)$ of Mn70Fe30 (a1, a2), Mn70Fe30 Ti20 (b1, b2), Mn70Fe30_Zr20 (c1, c2) and Mn70Fe30_Ce20 (d1, d2) particle surface: untreated (1) and after thermal cyclization (2)

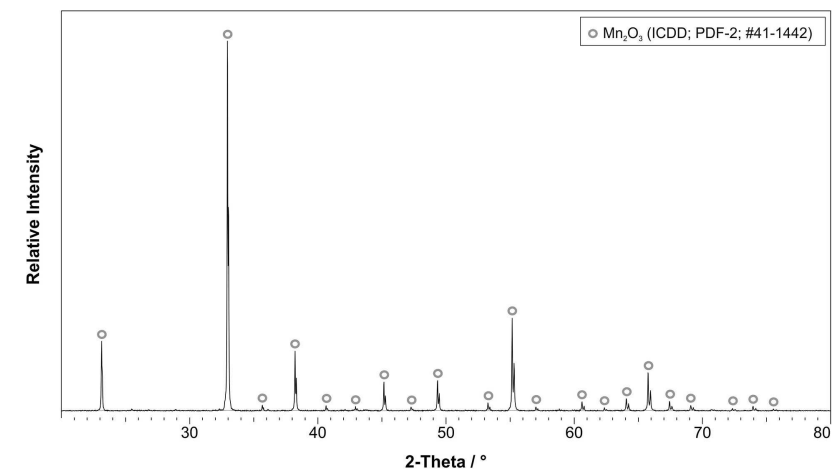

Figure 8. XRD pattern of the manganese-iron-oxide sample after thermal cyclization. $\mathrm{Mn}_{2} \mathrm{O}_{3}$ (space group: la3) can be detected. This pattern overlaps the $\mathrm{Fe}_{2} \mathrm{O}_{3}$ pattern (ICDD; PDF-2; \#39-0238) (space group: la3), so that pure $\mathrm{Mn}_{2} \mathrm{O}_{3}$, pure $\mathrm{Fe}_{2} \mathrm{O}_{3}$, or $(\mathrm{Mn}, \mathrm{Fe})_{2} \mathrm{O}_{3}$ cannot be distinguished.

reaction over temperature variation, instead of oxygen pressure variation, chemical and thermal stresses cannot be separated completely. For this reason, additional "temperature shock" experiments were performed.

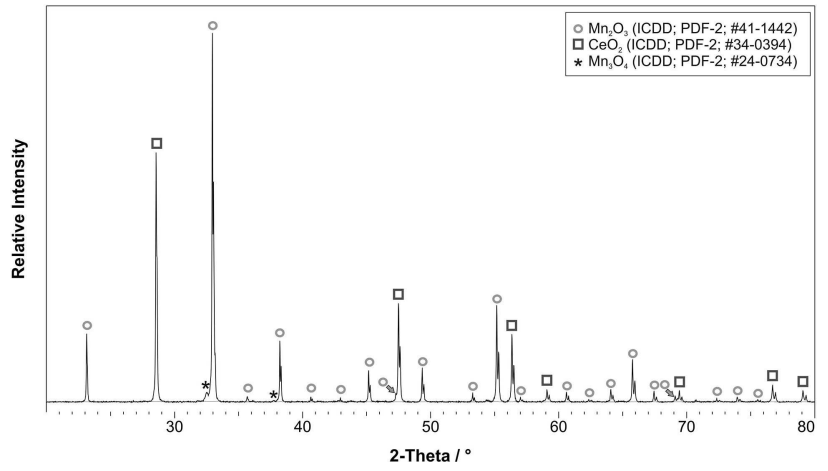

Figure 9. $\mathrm{XRD}$ pattern of the manganese-iron-oxide sample with the addition of $\mathrm{CeO}_{2}$ after thermal cyclization. $\mathrm{Mn}_{2} \mathrm{O}_{3}$ (space group: la3), $\mathrm{CeO}_{2}$ (space group: $\mathrm{Fm} 3 \mathrm{~m}$ ), and $\mathrm{Mn}_{3} \mathrm{O}_{4}$ (space group: $141 /$ amd) can be detected. As described in Figure 8 overlap with the $\mathrm{Fe}_{2} \mathrm{O}_{3}$ pattern (ICDD; PDF-2; \#39-0238) (space group: la3) is possible, so that pure $\mathrm{Mn}_{2} \mathrm{O}_{3}$, pure $\mathrm{Fe}_{2} \mathrm{O}_{3}$, or $(\mathrm{Mn}, \mathrm{Fe})_{2} \mathrm{O}_{3}$ cannot be distinguished.

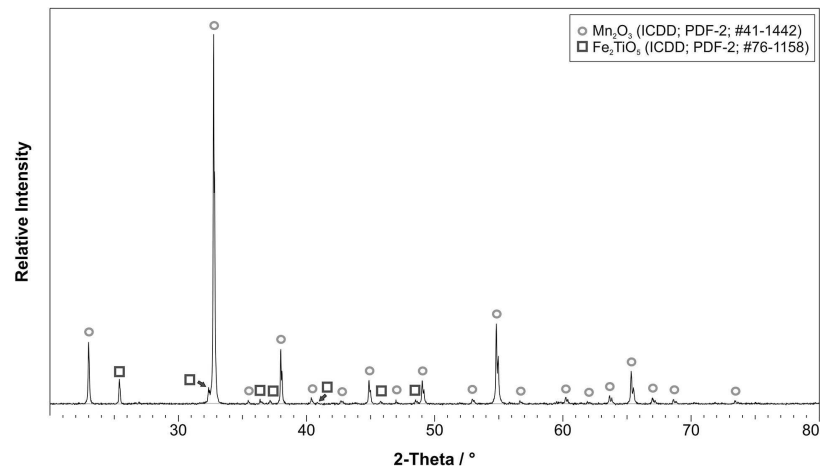

Figure 10. XRD pattern of the manganese-iron-oxide sample with the addition of $\mathrm{TiO}_{2}$ after thermal cyclization. $\mathrm{Mn}_{2} \mathrm{O}_{3}$ (space group: la3) and $\mathrm{Fe}_{2} \mathrm{TiO}_{5}$ (space group: $\mathrm{Cmcn}$ ) can be detected. As described in Figure 8 overlap with the $\mathrm{Fe}_{2} \mathrm{O}_{3}$ pattern (ICDD; PDF-2; \#39-0238) (space group: la3) is possible, so that pure $\mathrm{Mn}_{2} \mathrm{O}_{3}$, pure $\mathrm{Fe}_{2} \mathrm{O}_{3}$, or a $(\mathrm{Mn}, \mathrm{Fe})_{2} \mathrm{O}_{3}$ cannot be distinguished.

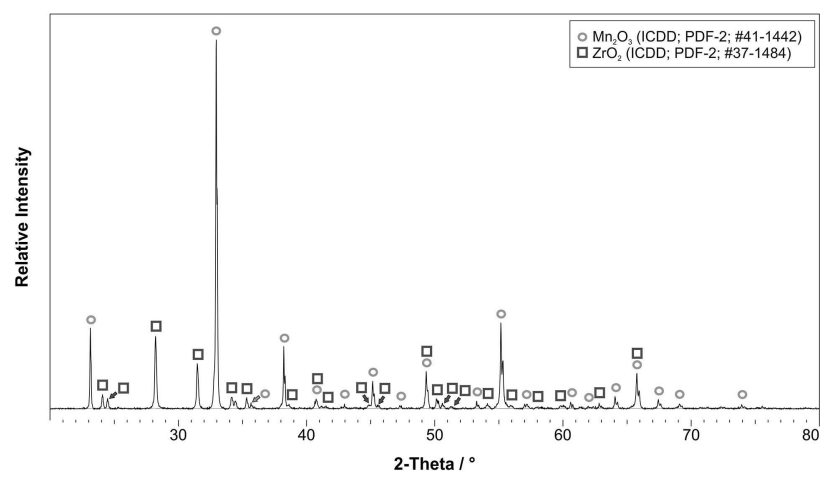

Figure 11. XRD pattern of the manganese-iron-oxide sample with the addition of $\mathrm{ZrO}_{2}$ after 30 temperature cycles. $\mathrm{Mn}_{2} \mathrm{O}_{3}$ (space group: la3) and $\mathrm{ZrO}_{2}$ (space group: P21/a) can be detected. As described in Figure 8 overlap with the $\mathrm{Fe}_{2} \mathrm{O}_{3}$ pattern (ICDD; PDF-2; \#39-0238) (space group: la3) is possible, so that pure $\mathrm{Mn}_{2} \mathrm{O}_{3}$, pure $\mathrm{Fe}_{2} \mathrm{O}_{3}$, or a $(\mathrm{Mn}, \mathrm{Fe})_{2} \mathrm{O}_{3}$ cannot be distinguished. 


\section{Effect of Temperature Shocks}

The effect of thermal strain on Mn70Fe30, Mn70Fe30_Ce20, and Mn70Fe30_Zr20 samples was investigated by applying high cooling rates to the packed bed. Fifteen subsequent cycles in air and in $\mathrm{N}_{2}$ were performed. Since Mn70Fe30_Ti20 showed no stable redox reaction in the previous cyclization test, it was excluded from further examination. A nitrogen atmosphere prohibits the re-oxidation of previously reduced manganese-iron oxide particles, whereas an air atmosphere allows a re-oxidation reaction. It must be noted that due to the fast average cooling rate of $110 \pm 4 \mathrm{~K} \mathrm{~min}^{-1}$, a complete conversion was not reached in air. In general, conversion decreased with cycle number for all samples. While a conversion of $77.7 \%$ for reduction and $76.9 \%$ for oxidation of $\mathrm{Mn} 70 \mathrm{Fe} 30$ was achieved in the first cycle, the conversion dropped to $26.9 \%$ for reduction and $31.1 \%$ for oxidation in the $15^{\text {th }}$ cycle. Mn70Fe30_Ce20 and Mn70Fe30_Zr20 indicated a similar behavior with a decrease of oxidation conversion of $64.4 \%$ to $21.2 \%$ and $48.8 \%$ to $5.1 \%$ respectively.

However, a direct comparison with the experiments performed in $\mathrm{N}_{2}$ showed clear effects that could be ascribed to the chemical reaction. The differential particle size distribution after a temperature shock test in air atmosphere showed an agglomeration of Mn70Fe30_Ce20 and, especially, Mn70Fe30 particles (Figure 12a). In contrast, thermal strain seemed to provoke splitting of Mn70Fe30_Zr20 particles to nearly half the original diameter.

The particle size distribution for Mn70Fe30_Ce20 and Mn70Fe30 showed no direct splitting effect when the air atmosphere allowed a redox reaction. In contrast, the temperature shock test in the nitrogen atmosphere (Figure 12b) did not initiate any agglomeration of any of the tested compositions. This means that the agglomeration of $\left(\mathrm{Mn}_{0.7} \mathrm{Fe}_{0.3}\right)_{2} \mathrm{O}_{3} /$ $\left(\mathrm{Mn}_{0.7} \mathrm{Fe}_{0.3}\right)_{3} \mathrm{O}_{4}$-based compositions is strongly related to the phase change caused by the redox reaction in the oxygen atmosphere and was not influenced by heating or cooling rates up to $110 \mathrm{~K} \mathrm{~min}^{-1}$. An apparent higher splitting of the Mn70Fe30_Zr20 sample in the nitrogen atmosphere than in the air atmosphere could be caused by a stronger reduced phase or experimental variance in sieving due to a rather low mass of 10 to $12 \mathrm{~g}$ of sample. However, Mn70Fe30_Ce20 and Mn70Fe30_Zr20 developed higher particle splitting due to thermal stress than Mn70Fe30 particles (Figure 12b). It can be speculated that there could be a superposition of splitting and subsequent agglomeration process for Mn70Fe30_Ce20 because Mn70Fe30_Ce20 indicated minor particle splitting during the temperature shock test in the nitrogen atmosphere but no particle splitting when the air atmosphere allowed for a redox reaction. In the end, the chemical reaction seemed to provoke the agglomeration of unsupported manganese-ironoxide, and thermal gradients induced the splitting of $\mathrm{ZrO}_{2}-$ upported manganese-iron-oxide particles.

The morphology on the particle surface especially of Mn70Fe30 and Mn70Fe30O_Ce20 changed with the 15 temperature shocks in air or nitrogen (Figure 13 a1-b2). An EDX analysis of Mn70Fe30 after 15 temperature shocks in air
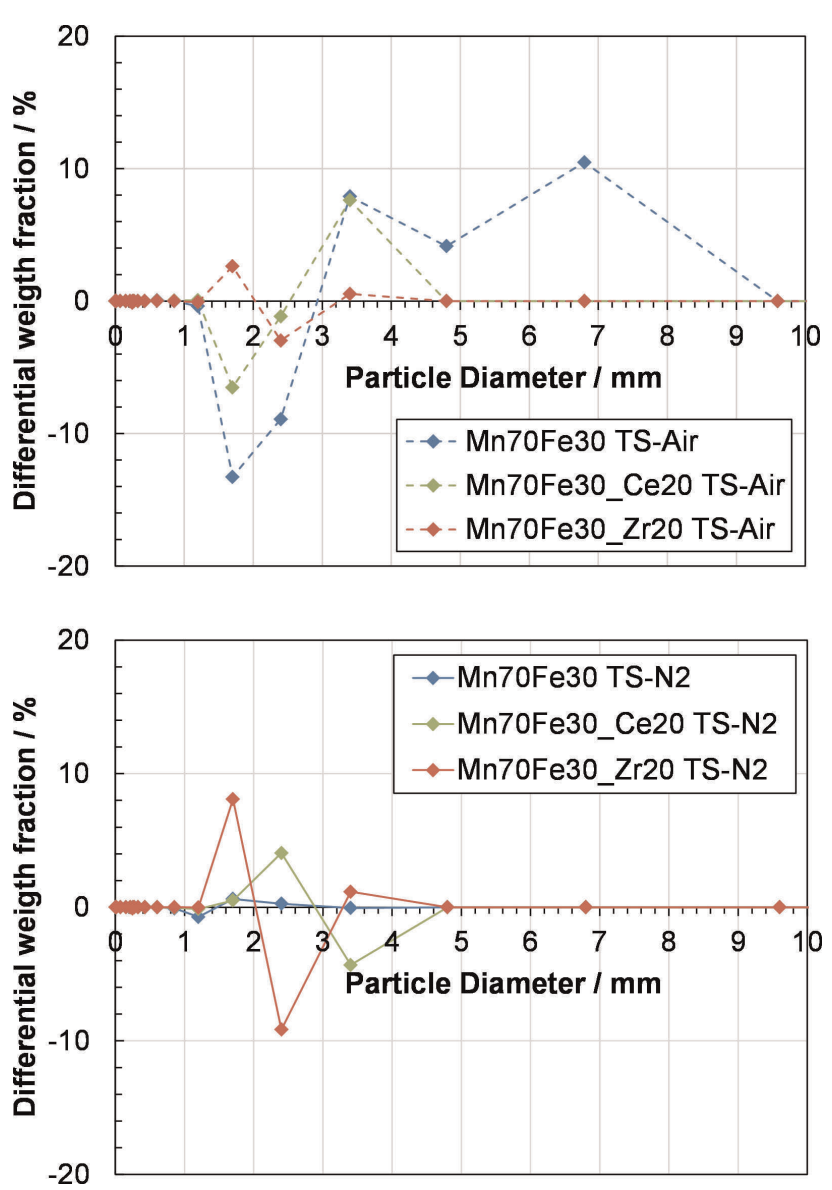

Figure 12. Differential particle size distribution after 15 temperature shocks in air (TS-Air) (a) and nitrogen atmospheres (TS-N2) (b) with Mn70Fe30, Mn70Fe30_Ce20, and Mn70Fe30_Zr20 in a packed bed reactor.

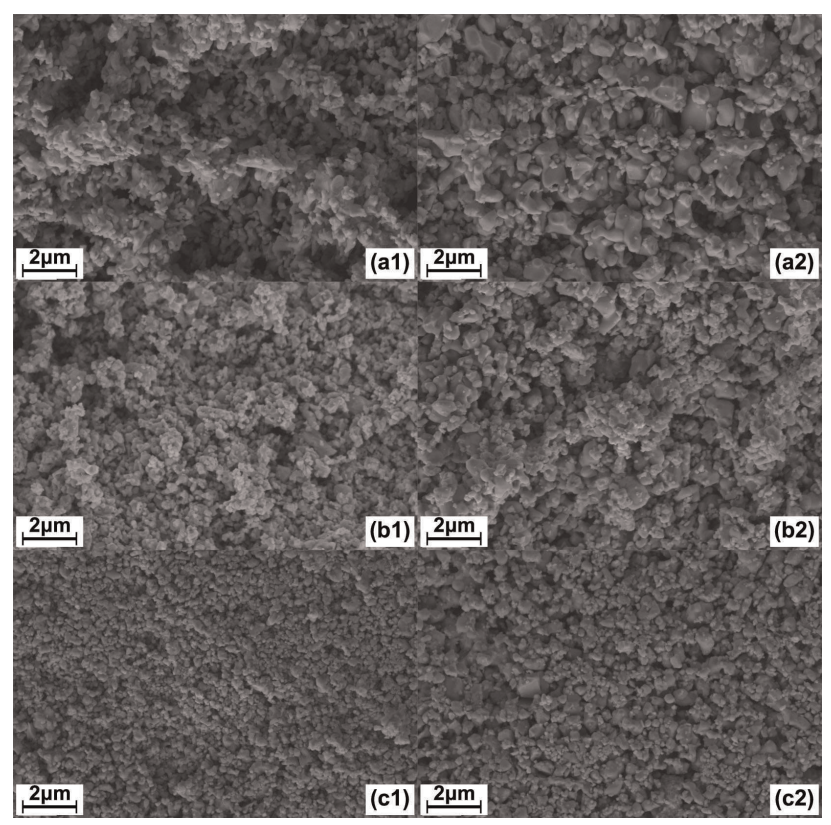

Figure 13. SEM images with $5.0 \mathrm{kV}$ acceleration voltage and working distances $8.0 \mathrm{~mm}(\mathrm{a} 1, \mathrm{a} 2, \mathrm{bl}, \mathrm{cl}, \mathrm{c} 2)$ and $8.1 \mathrm{~mm}$ (b2) of Mn70Fe30 (a1, a2), Mn70Fe30_Ce20 (b1, b2) and Mn70Fe30_Zr20 (c1, c2) particle surface: after 15 temperature shock in air (1) or in nitrogen (2) 
indicated Mn-rich areas as well as areas with an equal distribution of $\mathrm{Mn}$ and $\mathrm{Fe}$ cations. Whereas an even cation distribution was detected at the EDX measuring points of Mn70Fe30 after 15 temperature shocks in nitrogen. EDX analysis of Mn70Fe30_Zr20 after the temperature shock test in nitrogen revealed an irregular distribution of $\mathrm{Mn}, \mathrm{Fe}$, and $\mathrm{Zr}$ cations at the measuring points, whereas the EDX measuring points indicated an equal cation distribution in Mn70Fe30_Zr20 after the temperature shock test in air. However, optically, the surface morphology of Mn70Fe30_ $\mathrm{Zr} 20$ seems to be the most stable one compared to the other compositions after all experiments (Figure 7 c1-c2 and Figure $13 \mathrm{c} 1-\mathrm{c} 2$ ). Detailed EDX data can be found as supporting information.

\section{Particle Stability Investigation}

An attrition jet cup was utilized to estimate the tendency towards abrasion of all four compositions in untreated form and after the experiments above. The device was designed for quick screening tests with a low sample weight of $5 \mathrm{~g}$. The mechanical stress in this attrition jet cup is much greater than the stress found under moving bed conditions but may give an indication of the mechanical properties of the sample. The particle size distribution before and after an attrition rig test showed, that the test rig caused both abrasion and fragmentation. Previous examinations of oxygen carriers in the attrition jet cup indicated that the fine production follows either a linear trend over time or a logarithmic trend with a stabilized attrition rate after around $30 \mathrm{~min} \cdot{ }^{[54]}$ Therefore, a total attrition $\mathrm{A}_{\text {tot }}$ (eq. 2 in Experimental Section) and the attrition rate $A_{i}$ (eq. 3 in Experimental Section) are used to describe the attrition behavior. The attrition rate corresponds to the slope of the attrition curve over time between $30 \mathrm{~min}$ and $1 \mathrm{~h}$ operation. The total attrition $A_{\text {tot }}$ and the attrition rate $A_{i}$ in Figure 14 clearly demonstrate the improved attrition behavior of processed material with the addition of $\mathrm{ZrO}_{2}$ and $\mathrm{CeO}_{2}$.

Mn70Fe30_Zr20 promised high particle stability. In comparison to untreated particles, thermal stress, induced with temperature shock test in air or nitrogen, had only a minor effect on particle stability according to the attrition test
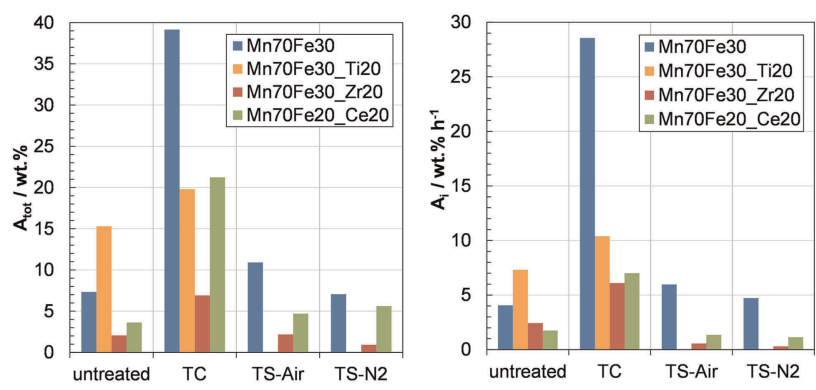

Figure 14. The total attrition (a) and the slope of the attrition curve of the last $30 \mathrm{~min}$ (b) of $1 \mathrm{~h}$ operation in the attrition jet cup of untreated particles and processed in thermal cyclization (TC) or temperature shock (TS) in air or nitrogen. method. Fifteen temperature shocks even improved the attrition resistance of $\mathrm{Mn} 70 \mathrm{Fe} 30 \_Z$ Z20 (Figure 14b). In contrast, 30 temperature cycles increased the total attrition and attrition slope of all material compositions, especially of the unsupported manganese-iron oxide samples. Again, $\mathrm{ZrO}_{2}$ was found to be the most promising supportive material regarding attrition resistance. However, the attrition rate after thermal cyclization tests with Mn70Fe30_Ce20 is in the range of the Mn70Fe30_Zr20 sample (Figure 14b). In ceramic research, $\mathrm{ZrO}_{2}$ is known to significantly improve the toughness of alumina due to its high fracture toughness, which describes the resistance of a material to the propagation of preexisting flaws. ${ }^{[60,61]}$

The attrition values over time are displayed in Figure 15 with silica sand as a reference material. The Mn70Fe30

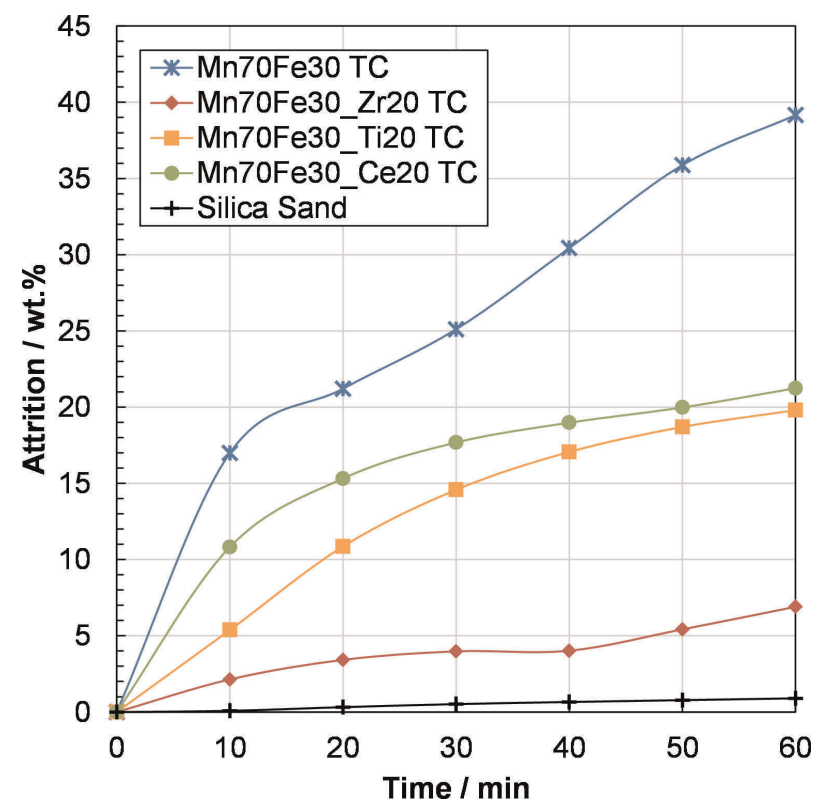

Figure 15. Attrition test of manganese-iron-oxide samples after thermal cyclization. Silica sand is the reference.

sample indicates a linear attrition rate, while the logarithmic attrition curves of Mn70Fe30_Ce20 and Mn70Fe30_Ti20 reach a stable but high level in the figure.

The strong agglomeration tendency and low particle stability (abrasion and disintegration) of Mn70Fe30, which is mainly caused by the chemical stress, can be ameliorated by supporting the manganese-iron oxide with $\mathrm{ZrO}_{2}$ or $\mathrm{CeO}_{2}$. From a technical point of view, the choice of modified material depends mainly on the mechanical and thermal stress the particles will experience in the chosen reactor and process concept. In applied reactor concepts, which cause high mechanical stress, e.g. a fluidized bed reactor, Mn70Fe30_ $\mathrm{Zr} 20$ is the favored composition of the investigated materials in this paper. The attrition test and the 30 temperature cycles proved strong particle stability. However, in comparison to the other compositions, Mn70Fe30_Zr20 indicated a tendency to particle splitting when high temperature gradients oc- 
curred. Considering reactor or process concepts with lower attrition risk, e.g. a packed bed, Mn70Fe30_Ce20 showed advantages over Mn70Fe30_Zr20 particles since it reached the highest oxidation conversion of all the modified particles. Even though Mn70Fe30_Ce20 shows the highest attrition in total numbers for the supported manganese-iron oxides, the slope of the attrition curve (tendency for stabilization) is similar to the results found using Mn70Fe30_Zr20 and a major improvement over $\mathrm{Mn} 70 \mathrm{Fe} 30$ particles. In conclusion, supporting $\mathrm{Mn} 70 \mathrm{Fe} 30$ with $\mathrm{ZrO}_{2}$ or $\mathrm{CeO}_{2}$ promises a prolonged mechanical particle lifetime. However, it must be noted that the production process influences the overall stability behavior of the particles. In future research, an optimal ratio of active manganese-iron-oxide particles to inert $\mathrm{ZrO}_{2}$ or $\mathrm{CeO}_{2}$ content will be addressed in terms of particle stability, agglomeration tendency, and reaction conversion.

\section{Conclusions}

The reactivity and particle stability of $\left(\mathrm{Mn}_{0.7} \mathrm{Fe}_{0.3}\right)_{2} \mathrm{O}_{3}$ as an active material supported by $20 \mathrm{wt}$ \% of either $\mathrm{CeO}_{2}, \mathrm{ZrO}_{2}$, or $\mathrm{TiO}_{2}$ was tested in a packed bed reactor and with an attrition test rig. From a technical engineering standpoint, the following conclusions can be drawn:

- Mn-Fe oxides are very well suited as thermochemical storage material and oxygen carrier material for chemicallooping combustion.

- Pure $\left(\mathrm{Mn}_{0.7} \mathrm{Fe}_{0.3}\right)_{2} \mathrm{O}_{3}$ showed the highest reactivity and redox conversion. However, it also showed a great tendency towards agglomeration and low particle stability, which reduces the expected lifetime of the particle. Therefore, a modification of this material is mandatory, despite the drawback of reduced energy density.

- The addition of $\mathrm{TiO}_{2}$ led to a deactivation of the manganese-iron oxide by forming pseudobrookite.

- Pure $\left(\mathrm{Mn}_{0.7} \mathrm{Fe}_{0.3}\right)_{2} \mathrm{O}_{3}$ and $\left(\mathrm{Mn}_{0.7} \mathrm{Fe}_{0.3}\right)_{2} \mathrm{O}_{3}$ supported with $\mathrm{CeO}_{2}$ or $\mathrm{ZrO}_{2}$ showed sufficient cycle stability. The reaction rate was faster with the addition of $\mathrm{CeO}_{2}$ than with $\mathrm{ZrO}_{2}$ under the experimental conditions, but was still slower than with pure $\left(\mathrm{Mn}_{0.7} \mathrm{Fe}_{0.3}\right)_{2} \mathrm{O}_{3}$. Consequently, the operational conditions must be adjusted (e.g. a longer reaction time) to avoid incomplete conversion.

- All investigated additives hindered or clearly decreased the agglomeration and improved the particle strength of manganese-iron-oxide particles. Especially $\mathrm{ZrO}_{2}$ promises a higher resistance towards attrition. A variation of the $\mathrm{CeO}_{2}$ or $\mathrm{ZrO}_{2}$ content should be addressed in future research to optimize the particle from the attrition, agglomeration, and reaction rate standpoints for use as thermochemical storage material or oxygen carrier.

\section{Experimental Section}

\section{Materials Preparation}

The Flemish Institute for Technological Research (VITO) in Belgium produced the particles with a build-up granulation technique by mixing the raw materials $\mathrm{Mn}_{3} \mathrm{O}_{4}$ (Chemalloy, Trimanox), $\mathrm{Fe}_{2} \mathrm{O}_{3}$ (Alfa Aesar, 99\%) and one of the supports $\mathrm{TiO}_{2}$ (Venator, Hombikat ${ }^{\mathrm{TM}} \mathrm{M} 211$ ), $\mathrm{CeO}_{2}$ (American Elements, $99 \%$ ) or $\mathrm{ZrO}_{2}$ (Saint Gobain, $99.9 \% \mathrm{ZrO}_{2}+\mathrm{HfO}_{2}$ ). A pretreatment in air at $800^{\circ} \mathrm{C}$ for $10 \mathrm{~h}$ allowed $\mathrm{Mn}_{3} \mathrm{O}_{4}$ and $\mathrm{Fe}_{2} \mathrm{O}_{3}$ to change into the bixbyite $(\mathrm{Mn}, \mathrm{Fe})_{2} \mathrm{O}_{3}$ phase. After granulation, the particles were sieved to a size between 2 and $3 \mathrm{~mm}$.

\section{Materials Characterization}

The weight loss due to reduction was measured with a simultaneous thermal analyzer from Netzsch (STA 449 F3 Jupiter ${ }^{\circledR)}$ to confirm equation (1). Two particles with a total mass of $30 \mathrm{mg}$ were oxidized at $850^{\circ} \mathrm{C}$ for $5 \mathrm{~h}$ in a $\mathrm{Pt} / \mathrm{Rh}$ crucible without a cap in an atmosphere containing $20 \%$ oxygen (Linde, $99.995 \%$ ) and $80 \%$ nitrogen (Linde, $99.999 \%$ ). The reduction was initiated by increasing the temperature with a heating rate of $20 \mathrm{~K} \mathrm{~min}^{-1}$ up to $1050^{\circ} \mathrm{C}$ in a nitrogen atmosphere and maintaining the temperature for $5 \mathrm{~h}$. A total gas flow of $100 \mathrm{mlmin}^{-1}$ was kept constant for the entire test.

An analysis of crystalline phases of manganese-iron-oxide particles was performed with an X-ray diffractometer (Bruker D8 Advance with $\mathrm{Cu}-\mathrm{Ka}_{1,2}$ radiation). Scanning electron microscopy (Zeiss Ultra 55) gave information about the shape and morphology of the particles and their polished microsection in combination with energy dispersive X-ray point measurements (Oxford Inca Penta FETX3). EDX measurements were performed with the secondary electron detector at a working distance of $8 \mathrm{~mm}$ with accelerating voltage of $15.0 \mathrm{~kW}$ and are listed as supporting information. Oxygen has been detected with EDX but is not listed in the supporting information, due to inaccuracy of the EDX measuring method in case of oxygen.

The bulk density was measured by filling and weighing a $50 \mathrm{ml}$ glass cylinder with 2-3 $\mathrm{mm}$ particles.

A customized jet cup is available at Chalmers University of Technology in Gothenburg, Sweden, to evaluate the attrition resistance of the oxygen carriers used for chemical looping combustion. A detailed description of the attrition rig setup can be found in ${ }^{[54]}$ A sample mass of $5 \mathrm{~g}$ was fit into an attrition cup and was fluidized with a moisturized air flow entering the cup through a nozzle. The particles were fluidized into a settling

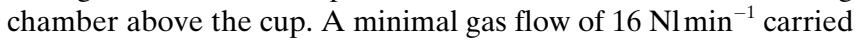
fines with a diameter below $10 \mu \mathrm{m}$ through the settling chamber to a particle filter at the top of the chamber, since the terminal velocity of the densest particles equals the gas velocity in the widest part of the settling chamber. The change of filter weight at the gas exit corresponded to the fine production during the measuring time. The total fine production $\mathrm{A}_{\mathrm{tot}}$ caused by attrition for a measuring period of $1 \mathrm{~h}$ was calculated according to equation (2).

$A_{\text {tot }}=100 * \frac{m_{f, 1 h}-m_{f, \text { start }}}{m_{s}}(\mathrm{wt} . \%)$

The attrition rate is describes the trend of the attrition curve between $30 \mathrm{~min}$ and $1 \mathrm{~h}$ operation and is calculated according to equation (3). 


$$
A_{i}=100 * \frac{60}{30} * \frac{m_{f, 1 h}-m_{f, 30 \min }}{m_{s}}\left(\mathrm{wt} . \% \mathrm{~h}^{-1}\right)
$$

In equations (2) and (3), $m_{s}$ is the sample weight placed in the cup and $m_{f, t}$ equals the filter weight for a given operation time $\mathrm{t}$.

\section{Experiments in a Packed Bed Reactor}

Thermal cyclization tests and temperature shock tests were performed in a packed bed reactor. Particles were placed on a porous quartz plate in a glass tube, and gas was introduced at the bottom of the reactor (Figure 16). A detailed description of the reactor setup can be found in. ${ }^{[11]}$

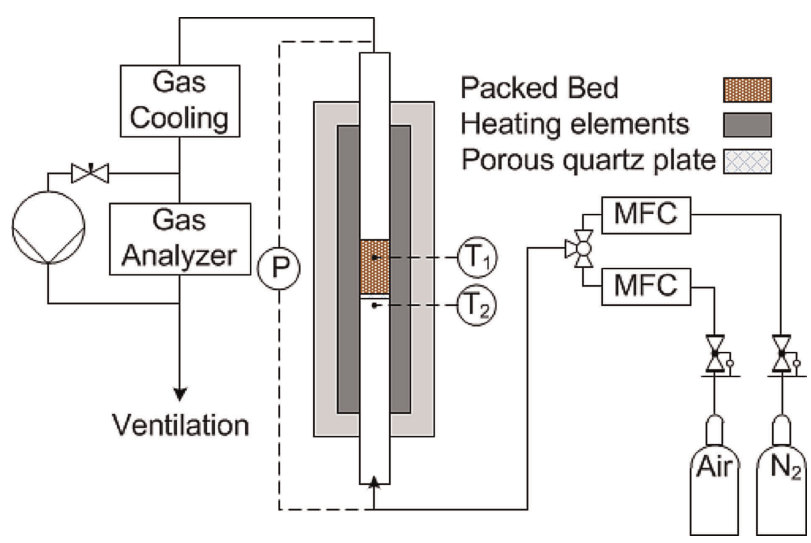

Figure 16. Schematic setup of the packed bed reactor.

The set temperature for the oven was controlled by two thermocouples (Pentronic $\mathrm{CrAl} / \mathrm{NiAl}$ with inconel-600), each enclosed in a quartz thermowell. One was placed $25 \mathrm{~mm}$ above the quartz plate $\left(\mathrm{T}_{1}\right)$, and one was placed $5 \mathrm{~mm}$ below the plate $\left(T_{2}\right)$. The bed height always exceeded $25 \mathrm{~mm}$ and thermocouple $\mathrm{T}_{1}$ was employed to determine the bed temperature. The reactor could be used as a packed bed or fluidized bed depending on gas velocity. A gas flow of $3 \mathrm{Nl} \mathrm{min}{ }^{-1}$ was chosen for all experiments, which resulted in a packed bed operation since the flow was well below the minimum fluidization velocity.

Thermal cyclization was conducted by varying the temperature with a heating rate of $20 \mathrm{~K} \mathrm{~min}^{-1}$ between $850^{\circ} \mathrm{C}$ for oxidation and $1050^{\circ} \mathrm{C}$ for reduction in the packed bed reactor. The redox reaction was initiated by changing the temperature. An isothermal step followed each heating and cooling phase for $12 \mathrm{~min}$ at $1050^{\circ} \mathrm{C}$ and for $6 \mathrm{~min}$ at $850^{\circ} \mathrm{C}$. 30 redox cycles were performed with a mass of $21 \mathrm{~g}$ manganese-iron oxide material or $26 \mathrm{~g}$ supported manganese-iron oxide material to compensate for the possibly inert additive. The thermal cyclization experiments were executed on two consecutive days, and the packed bed reactor was cooled to ambient temperature in air at the end of the first day.

The fast cooling rates for the temperature shock tests were achieved by opening the oven circa $4 \mathrm{~cm}$ to permit effective cooling rates of $110 \pm 4 \mathrm{~K} \mathrm{~min}^{-1}$. A sample of $10 \mathrm{~g}$ manganeseiron-oxide particles or $12 \mathrm{~g}$ manganese-iron-oxide with an additive was placed on the quartz plate for temperature shock test. The temperature shock tests were performed 15 times in air for an oxidizing environment and 15 times in a pure nitrogen atmosphere for a reducing environment.

\section{Acknowledgements}

The authors acknowledge the work of the late Dongmei Zhao (deceased Dec. 18, 2016). At the time of her death, she was deeply involved in this research and made many important contributions. Financial support was provided by DLR internal funding and ÅFors.

\section{Conflict of Interest}

The authors declare no conflict of interest.

Keywords: Manganese · Iron · Redox chemistry
Thermochemistry Particle stability

[1] A. Lyngfelt, B. Leckner, T. Mattisson, Chem. Eng. Sci. 2001, 56, 3101-3113

[2] T. Mattisson, A. Lyngfelt, H. Leion, Int. J. Greenhouse Gas Control 2009, 3, 11-19

[3] A. Abad, I. Adánez-Rubio, P. Gayán, F. García-Labiano, L. F. de Diego, J. Adánez, Int. J. Greenhouse Gas Control 2002, 6, 189-200

[4] L. Xu, H. Sun, Z. Li, N. Cai, Appl. Energy,2016, 162, 940-947

[5] A. Lyngfelt, C. Linderholm, Energy Procedia 2014, 63, 98-112

[6] J. Ströhle, M. Orth, B. Epple, Appl. Energy 2015, 157, 288-294

[7] M. Arjmand, A. Hedayati, A.-M. Azad, H. Leion, M. Rydén, T. Mattisson, Energy Fuels 2013, 27, 4097-4107

[8] N. M. Pour, G. Azimi, H. Leion, M. Rydén, T. Mattisson, A. Lyngfelt, Energy Technol. 2014, 2, 469-479

[9] M. Arjmand, H. Leion, A. Lyngfelt, T. Mattisson, Int. J. Greenhouse Gas Control 2012, 8, 56-60

[10] A. Steinfeld, Sol. Energy 2005, 78, 603-615

[11] D. Marxer, P. Furler, M. Takacs, A. Steinfeld, Energy Environ. Sci. 2017, 10, 1142-1149

[12] L. O. Schunk, P. Haeberling, S. Wepf, D. Wuillemin, A. Meier, A. Steinfeld, J. Sol. Energy Eng. 2008, 130, 021009

[13] N. Gokon, T. Mataga, N. Kondo, T. Kodama, Int. J. Hydrogen Energy 2011, 36, 4757-4767

[14] S. Abanades, P. Charvin, G. Flamant, Chem. Eng. Sci. 2007, 62, 63236333

[15] R. B. Diver, J. E. Miller, M. D. Allendorf, N. P. Siegel, R. E. Hogan, J. Sol. Energy Eng. 2008, 130, 041001-041001-8

[16] I. Ermanoski, N. P. Siegel, E. B. Stechel, J. Sol. Energy Eng. 2013, 135, 031002-031002-10

[17] E. Koepf, S. G. Advani, A. Steinfeld, A. K. Prasad, Int. J. Hydrogen Energy 2012, 37, 16871-16887

[18] P. Lichty, X. Liang, C. Muhich, B. Evanko, C. Bingham, A. W. Weimer, Int. J. Hydrogen Energy 2012, 37, 16888-16894

[19] L. J. Venstrom, R. M. De Smith, Y. Hao, S. M. Haile, J. H. Davidson, Energy Fuels 2014, 28, 2732-2742

[20] S. Abanades, H. I. Villafan-Vidales, Chem. Eng. J. 2011, 175, 368-375

[21] C. Agrafiotis, M. Roeb, M. Schmücker, C. Sattler, Sol. Energy. 2014, 102, 189-211.

[22] T. Block, M. Schmücker, Sol. Energy 2016, 126, 195-207

[23] A. J. Carrillo, J. Moya, A. Bayón, P. Jana, V. a. de la Peña O’Shea, M. Romero, J. Gonzalez-Aguilar, D. P. Serrano, P. Pizarro, J. M. Coronado, Sol. Energy Mater. Sol. Cells. 2014, 123, 47-57

[24] W. E. Wentworth, E. Chen, Sol. Energy. 1976, 18, 205-214.

[25] C. Prieto, P. Cooper, A. I. Fernández, Renewable Sustainable Energy Rev. 2016, 60, 909-929

[26] H. Zhang, J. Baeyens, G. Cáceres, J. Degrève, Y. Lv, Prog. Energy Combust. Sci. 2016, 53, 1-40

[27] M. Romero, A. Steinfeld, Energy Environ. Sci. 2012, 5, 9234-9245

[28] A. J. Schrader, A. P. Muroyama, P. G. Loutzenhiser, Sol. Energy 2015, 118, 485-495 
[29] E. Alonso, C. Pérez-Rábago, J. Licurgo, E. Fuentealba, C. A Estrada, Sol. Energy 2015, 115, 297-305

[30] M. Neises, S. Tescari, L. de Oliveira, M. Roeb, C. Sattler, B. Wong, Sol. Energy 2012, 86, 3040-3048

[31] A. S. Oles, G. S. Jackson, Sol. Energy 2015, 122, 126-147

[32] A. J. Schrader, G. De Dominicis, G. L. Schieber, P. G. Loutzenhiser, Sol. Energy 2017, 150, 584-595

[33] E. Alonso, F. Gomez-Garcia, J. Gozalez-Aguilar, M. Romero, Proceedings of the SolarPACES Conference, Spain 2011. 20-23.

[34] M. Wokon, A. Kohzer, M. Linder, Sol. Energy 2017, 153, 200-214

[35] S. Álvarez de Miguel, J. Gonzalez-Aguilar, M. Romero, Energy Procedia 2014, 49, 676-683

[36] J. V. Crum, B. J. Riley, J. D. Vienna, J. Am. Ceram. Soc. 2009, 92, 2378-2384

[37] L. Kjellqvist, M. Selleby, J. Phase Equilib. Diffus. 2010, 31, 113-134

[38] A. Muan, S. Sōmiya, Am. J. Sci. 1962, 260, 230-240

[39] D. G. Wickham, J. Inorg. Nucl. Chem. 1969, 31, 313-320

[40] L. André, S. Abanades, L. Cassayre, J. Solid State Chem. 2017, 253, $5-14$

[41] A. Carrillo, D. P. Serrano, P. Pizarro, J. M. Coronado, ChemSusChem. 2015, 8, 1947-1954

[42] M. Wokon, T. Block, S. Nicolai, M. Linder, M. Schmücker, Sol. Energy 2017, 153, 471-485

[43] G. Azimi, H. Leion, M. Ryden, T. Mattisson, A. Lyngfelt, Energy Fuels 2013, 27, 367-377

[44] C. H. Bartholomew, Appl. Catal. A 2001, 212,17-60

[45] Y. Zhong, Z. Wang, Z. Guo, Q. Tang, Powder Technol. 2014, 256, 13 19

[46] T. A. Brown, F. Scala, S. A. Scott, J. S. Dennis, P. Salatino, Chem. Eng. Sci. 2012, 71, 449-467

[47] C. R. Bemrose, J. Bridgwater, Powder Technol. 1987, 49, 97-126

[48] S. Bhavsar, B. Tackett, G. Veser, Fuel 2014, 136, 268-279

[49] A. Khadilkar, P. L. Rozelle, S. V. Pisupati, Powder Technol. 2014, 264, 216-228
[50] Y. De Vos, M. Jacobs, P. Van Der Voort, I. Van Driessche, F. Snijkers, A. Verberckmoes, Chem. Eng. J. 2017, 309, 824-839

[51] G. Azimi, H. Leion, T. Mattisson, M. Ryden, F. Snijkers, A. Lyngfelt, Ind. Eng. Chem. Res. 2014, 53, 10358-10365

[52] M. Abián, A. Abad, M. T. Izquierdo, P. Gayán, L. F. de Diego, F. García-Labiano, J. Adánez, Fuel 2017, 195, 38-48

[53] M. Jacobs, J. Van Noyen, Y. Larring, M. Mccann, M. Pishahang, S. Amini, M. Ortiz, F. Galluci, M. V. Sint-Annaland, D. Tournigant, E. Louradour, F. Snijkers, Appl. Energy 2015, 157, 374-381

[54] M. Rydén, P. Moldenhauer, S. Lindqvist, T. Mattisson, A. Lyngfelt, Powder Technol. 2014, 256, 75-86

[55] A. Tilland, J. Prieto, D. Petitjean, E. Schaer, Chem. Eng. J. 2016, 302, 619-632

[56] I. Barin in Thermochemical data of pure substances, Vol. 3 (Eds.: K Sora, J. Gardiner), VCH Verlagsgesellschaft mbH, Weinheim, 1995.

[57] A. Cabello, P. Gayán, F. García-Labiano, L. F. de Diego, A. Abad, J. Adáne, Fuel Process. Technol. 2016, 148, 188-197

[58] F. Scala, F. Montagnaro, P. Salatino, Energy Fuels 2007, 21, 25662572

[59] B. Amblard, S. Bertholin, C. Bobin, T. Gauthier, Powder Technol. 2015, 274, 455-465

[60] N. Claussen, J. Am. Ceram. Soc. 1976, 59, 49-51

[61] S. Hori, M. Yoshimura, S. Sōmiya, J. Mater. Sci. Lett. 1985, 4, 413-416

[62] L. M. Anovitz, A. H. Treiman, E. J. Essene, B. S. Hemingway, E. F. Westrum Jr., V. J. Wall, R. Burriel, S. R. Bohlen in The Heat-capacity of ilmenite and phase equilibria in the system $\mathrm{Fe}$-Ti-O, Geochimica et Cosmochimica Acta 49, Pergamon Press Ltd., 1985, pp. 2027-2040.

Manuscript received: $\mathbf{\square}$,

Accepted Article published: April 25, 2018

Version of record online: April 26, 2018 


\section{FULL PAPER}

Particle degeneration and agglomeration is one challenge for an application of metal oxides in the discipline of thermochemical storage and chemical-looping combustion. By supporting manganese-iron oxide granules with additives, such as e.g. $\mathrm{ZrO}_{2}$ or $\mathrm{CeO}_{2}$, the tendency towards agglomeration and attrition can be minimized tremendously.

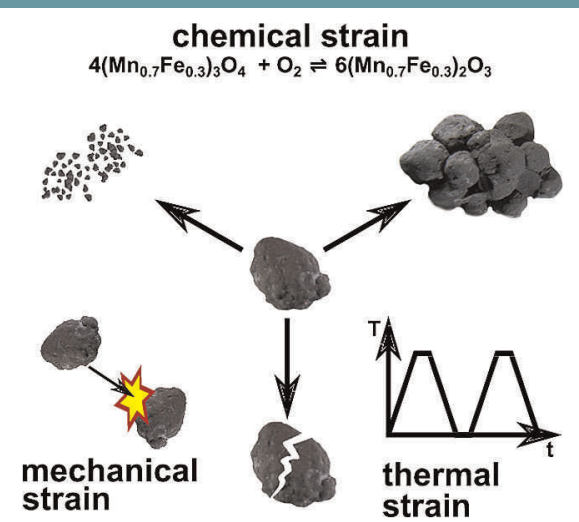

N. C. Preisner*, Dr. T. Block, Dr. M. Linder, Dr. H. Leion $1-13$

Stabilizing Particles of Manganeseiron Oxide with Additives for Thermochemical Energy Storage

\section{\#\# SPACE RESERVED FOR IMAGE AND LINK}

Share your work on social media! Energy Technology has added Twitter as a means to promote your article. Twitter is an online microblogging service that enables its users to send and read short messages and media, known as tweets. Please check the pre-written tweet in the galley proofs for accuracy. If you, your team, or institution have a Twitter account, please include its handle @username. Please use hashtags only for the most important keywords, such as \#catalysis, \#nanoparticles, or \#proteindesign. The ToC picture and a link to your article will be added automatically, so the tweet text must not exceed 250 characters. This tweet will be posted on the journal's Twitter account (follow us @EnergyTechnology) upon publication of your article in its final (possibly unpaginated) form. We recommend you to re-tweet it to alert more researchers about your publication, or to point it out to your institution's social media team.

\section{ORCID (Open Researcher and Contributor ID)}

Please check that the ORCID identifiers listed below are correct. We encourage all authors to provide an ORCID identifier for each coauthor. ORCID is a registry that provides researchers with a unique digital identifier. Some funding agencies recommend or even require the inclusion of ORCID IDs in all published articles, and authors should consult their funding agency guidelines for details. Registration is easy and free; for further information, see http://orcid.org/.
N. C. Preisner
Dr. T. Block
Dr. M. Linder
Dr. H. Leion 